1991-3 for people aged 65-74 years (standardised to the European standard population), who were thus born around 1922 (range 1917-1928). Infant death rates for 1921-3 (or 1920-4 when 1921-3 rates were not available) were obtained from various sources, including the UN Demographic Year Book. ${ }^{3}$ Infant death rates for 1991-3 were obtained from the WHO's Health for All database (www.who.dk/country/ country.htm) and the UN Demographic Year Book. The 27 countries for which all variables were available and where death registration is believed to be complete were included in the analyses. Standards of certification of cause of death will, however, vary across these countries.

The table shows strong correlations between infant mortality in the 1920 s and current mortality from stomach cancer. To examine the possible confounding effect of current circumstances, the table also shows correlations between adult mortality 1991-3 and infant mortality in the same period. For stomach cancer these correlations are appreciable but considerably smaller than the correlations with mortality at the time of birth. Partial correlation coefficients are shown in the bottom half of the table, where the correlations of adult mortality with infant mortality in one period have been adjusted for infant mortality in the other. These partial coefficients indicate that the association is almost exclusively with infant mortality at the time of birth.

The table also shows correlation coefficients for other causes of death. Mortality from respiratory tuberculosis is more strongly related to infant mortality at the time of birth than currently, in agreement with the notion that people dying of respiratory tuberculosis in old age have been initially infected during their early years. Lung cancer shows an appreciable inverse correlation with infant mortality at birth for women only. This may be because historical levels of infant mortality may provide an indication of women's position in society, which in turn is related to cohort differences in the uptake of tobacco smoking by women.

Coefficients for stroke and for coronary heart disease are strikingly different, as previously reported. ${ }^{4}$ Coronary heart disease shows the weakest correlations with historical levels of infant mortality of any of the causes in the table, and only weak correlations with current infant mortality, whereas stroke shows strong associations with both historical and current infant mortality.

\section{Comment}

Our analyses imply that that a poor environment during infancy and childhood, which is associated with high infant mortality, may explain some of the similarities in the descriptive epidemiology of stroke and stomach cancer. ${ }^{1}$ Risk of stroke may be influenced by undetermined infection(s) in childhood that may have similar epidemiological characteristics to $H$ pylori. The results also reinforce the large differences in the aetiology of stroke and coronary heart disease, ${ }^{5}$ with adverse circumstances during early life being considerably more important for stroke.

The idea for this work was jointly developed; DAL analysed the data and drafted the paper, which was revised by GDS. DAL is the guarantor.

Funding: None

Competing interests: None declared.

1 Davey Smith G, Hart C, Blane D, Hole D. Adverse socioeconomic conditions in childhood and cause specific adult mortality: prospective observational study. $B M J$ 1998;316:1631-5.

2 Parsonnett J. Helicobacter pylori and gastric adenocarcinoma. In: Parsonnet J, ed. Microbes and malignancy. Infection as a cause of human cancers. Oxford: Oxford University Press, 1999:372-408.

3 UN demographic yearbook. New York: United Nations, 1948-70.

4 Elford J, Ben-Shlomo Y. Geography and migration. In: Kuh D, Ben-Shlomo Y, eds. Life course influences on adult disease. Oxford: Oxford University Press, 1997:220-41.

5 Gale CR, Martyn CN. The conundrum of time trends in stroke. J R Soc Med 1997;90:138-43.

(Accepted 3 February 2000)

\title{
Role of C282Y mutation in haemochromatosis gene in development of type 2 diabetes in healthy men: prospective cohort study
}

\author{
Jukka T Salonen, Tomi-Pekka Tuomainen, Kimmo Kontula
}

Research Institute of Public Health and the

Department of Public Health and General Practice, University of Kuopio, PO Box 1627,70211 Kuopio, Finland Jukka T Salonen professor of epidemiology continued over
Type 2 diabetes mellitus is a common complication of iron overload diseases such as hereditary haemochromatosis. ${ }^{1}$ A gene mutation (HFE C282Y) has recently been identified that strongly predisposes to haemochromatosis when present in homozygous form. ${ }^{2}$ Because of the notable prevalence of this gene mutation (10.9\% in the United Kingdom), ${ }^{3}$ any disorder related to it has public health importance. We tested the hypothesis that a carrier status for the C282Y mutation predicts the development of type 2 diabetes.

\section{Participants, methods, and results}

We conducted a population based, prospective, four year follow up study of men aged 54 or 60 in the Kuo- pio ischaemic heart disease risk factor study, a population study in eastern Finland. ${ }^{4}$ Of 633 eligible men, 555 $(88 \%)$ participated in the four year follow up. Of these, 508 were not diabetic (fasting blood glucose concentration $<6.7 \mathrm{mmol} / \mathrm{l}$ and no treatment for diabetes) at baseline. A participant was defined diabetic at the end of the follow up if he had a fasting blood glucose concentration $\geqslant 6.7 \mathrm{mmol} / \mathrm{l}$, a blood glucose concentration of $\geqslant 10.0 \mathrm{mmol} / 1$ two hours after a glucose load, or clinical diagnosis of diabetes requiring dietary, oral, or insulin treatment.

The $\mathrm{G}$ to A transition at nucleotide 845 of the HFE cDNA, resulting in a substitution of tyrosine for cysteine at codon 282, was assayed by a solid phase minisequencing technique. ${ }^{5}$ The other strongest 
predictors of diabetes-blood glucose and serum fatty acid concentration, ${ }^{4}$ maximal oxygen uptake, and body mass index-were assessed with standard methods. We estimated odds ratios for developing diabetes with adjustment for risk factors using multivariate logistic regression models. All tests of significance were two sided.

We found one homozygote and 34 heterozygotes for the HFE C282Y mutation, giving a carrier frequency of $6.9 \%$ (including the homozygote). Four $(11 \%)$ of the carriers and $23(5 \%)$ of the 473 non-carriers developed diabetes during the four year follow up. In a multivariate logistic model, significant predictors of diabetes, assessed at baseline, were high body mass index, high ratio of saturated to the sum of polyunsaturated and monounsaturated fatty acids in serum, and the occurrence of the C282Y mutation (table). The Tyr282 allele carriers had an odds ratio of over 3.5 (95\% confidence interval 1.02 to 12.1, $\mathrm{P}=0.047)$ for developing diabetes, compared with non-carriers.

\section{Comment}

Our prospective cohort study suggests an association between the common HFE gene mutation and the incidence of type 2 diabetes. Although our study was relatively small, our data support the theory that abnormalities of iron homeostasis contribute to the development of type 2 diabetes. If the observed association were causal, the C282Y mutation would account for as much as $15 \%$ of the incidence of type 2 diabetes in northern European populations with a carrier frequency of $7 \%$. As the incidence of diabetes in northern Europe is among the highest in the world and rising, screening for C282Y mutation by DNA analysis, monitoring of iron status, and iron depleting treatment could potentially constitute new important measures in the primary prevention of diabetes. The C282Y mutation also predisposes to coronary heart disease. ${ }^{5} \mathrm{It}$

Odds ratios for carrier status for HFE C282Y mutation and other strongest predictors of diabetes in four year follow up of 508 non-diabetic men

\begin{tabular}{|c|c|c|}
\hline Predictor & $\begin{array}{c}\text { Odds ratio ( } 95 \% \text { confidence } \\
\text { interval }\end{array}$ & $P$ value \\
\hline C282Y mutation (yes $v$ no) & 3.51 (1.02 to 12.08) & 0.047 \\
\hline Body mass index $\left(\mathrm{kg} / \mathrm{m}^{2}\right)$ & 1.25 (1.12 to 1.41$)$ & $<0.001$ \\
\hline Serum fatty acid ratio* & 1.08 (1.01 to 1.15$)$ & 0.026 \\
\hline Maximal oxygen uptake (I/min/100) & $0.93(0.86$ to 1.01$)$ & 0.078 \\
\hline
\end{tabular}

* Ratio of the sum of saturated fatty acid concentrations to the sum of concentrations of polyunsaturated and monounsaturated fatty acids, multiplied by 100 †Based on Wald $\chi^{2}$ statistic.

may therefore prove especially important to find out whether the $\mathrm{C} 282 \mathrm{Y}$ mutation increases the risk of myocardial infarction in people with type 2 diabetes.

Contributors:JTS, the principal investigator of the Kuopio ischaemic heart disease study, initiated and coordinated the research, formulated the primary study hypothesis, performed the data analysis, and drafted the manuscript. He is also the guarantor of the study. T-PT discussed core ideas and participated in writing the paper. KK supervised the genotypings, discussed core ideas, and participated in writing the paper.

Funding: This work was supported by the Academy of Finland (grants for projects \#41471, 1041086, 2041022 to JTS and \#35313 to KK) and by the United States National Heart, Lung, and Blood Institute (grant HL44199 to George A Kaplan for the Kuopio ischaemic heart disease study four year follow up study).

Competing interests: None declared.

Research Institute of Public Health, University of Kuopio, Kuopio, Finland

Tomi-Pekka

Tuomainen

research fellow

Department of

Medicine, Helsinki

University Central

Hospital, Helsinki,

Finland

Kimmo Kontula

professor of molecular medicine

Correspondence to: J T Salonen jukka.salonen@uku.fi

1 Yaouanq JM. Diabetes and haemochromatosis: current concepts, management and prevention. Diabetes Metab 1995;21:319-29.

2 Feder JN, Gnirke A, Thomas W, Tsuchihashi Z, Ruddy DA, Basava A, et al. A novel MHC class I-like gene is mutated in patients with hereditary haemochromatosis. Nature Genet 1996;13:399-408.

3 Merryweather-Clarke AT, Pointon JJ, Shearman JD, Robson KJ. Global prevalence of putative haemochromatosis mutations. J Med Gene 1997;34:275-8

4 Salonen JT, Nyyssönen K, Tuomainen T-P, Mäenpää PH, Korpela H, Kaplan GA, et al. Increased risk of non-insulin dependent diabetes mellitus at low plasma vitamin $\mathrm{E}$ concentrations: a four year follow up study in men. BMJ 1995:311:1124-7.

5 Tuomainen T-P, Kontula K, Nyyssönen K, Lakka TA, Heliö T, Salonen JT Increased risk of acute myocardial infarction in carriers of the hemochromatosis gene Cys282Tyr mutation: a prospective cohort study in men in eastern Finland. Circulation 1999;100:1274-9.

(Accepted 24 February 2000)

\section{A patient who changed my life "You heard all wrong"}

"If India's family planning policy has to succeed you all have a part to play."

As final year medical students, all unmarried, from conservative backgrounds, even the most macho men in my class were beginning to wish that our project was something different, perhaps a nice nutrition study.

The teacher handed out oblong green coloured packets decorated with a red triangle, the family planning symbol. "Go forth, convert the village, do your mite."

We assiduously covered the 40 families we had been assigned, month after month, checking the empty containers and making sure that schedules were being followed.

In the fourth house, the woman hissed into my ear, "I was due four days ago."

I checked her packets and chart once more.

"Is the course completed?"

"Yes." She nodded her head vigorously.

"Each time?"

"Yes. I am nauseated, and I want to eat only lime pickle."

"Don't worry." I patted her back reassuringly. Three months later there was a distinct bulge in the lower part of her abdomen.
I escorted her back to the base hospital and consulted the professor.

"Sir, we were told that the pill was $99.9 \%$ effective. Her pregnancy test is positive."

He pushed his spectacles up on to his bald pate and turned to the patient, "Did you throw away the pills?"

"No, doctor."

"Did you take them regularly?"

"No."

I looked at her accusingly. "You told me you had not missed a single dose."

"No, doctor, you heard all wrong. I said that my husband did not miss a single dose."

Gita Mathai paediatrician, Vellore, Tamil Nadu, India

We welcome articles of up to 600 words on topics such as A memorable patient, A paper that changed my practice, My most unfortunate mistake, or any other piece conveying instruction, pathos, or humour. If possible the article should be supplied on a disk. Permission is needed from the patient or a relative if an identifiable patient is referred to. 